\title{
Gene expression profiles with cDNA microarray reveal RhoGDI as a predictive marker for paclitaxel resistance in ovarian cancers
}

\author{
TOMOKO GOTO ${ }^{1,4}$, MASASHI TAKANO ${ }^{2}$, MASARU SAKAMOTO ${ }^{4}$, AYAKO KONDO $^{4}$, JUNKO HIRATA ${ }^{2}$, \\ TSUNEKAZU KITA ${ }^{2}$, HITOSHI TSUDA ${ }^{3}$, YOSHIO TENJIN ${ }^{4}$ and YOSHIHIRO KIKUCHI ${ }^{2}$ \\ ${ }^{1}$ Department of Obstetrics and Gynecology, Saitama Medical College, 38 Morohongo, Moroyama, Iruma-gun, \\ Saitama 350-0495; Departments of ${ }^{2}$ Obstetrics and Gynecology and ${ }^{3}$ Pathology II, National Defense \\ Medical College, Tokorozawa, Saitama 359-8513; ${ }^{4}$ Department of Gynecology, \\ Sasaki Institute Kyoundo Hospital, Kanda-Surugadai, Tokyo 101-0062, Japan
}

Received September 6, 2005; Accepted November 2, 2005

\begin{abstract}
In the current study, we identified paclitaxelresistant related genes by comparing gene expression profiles of paclitaxel-resistant and parent ovarian cancer cell lines. Gene expression profiles of the human ovarian cancer cell line (KF28), cisplatin-resistant cell line (KFr13) induced from KF28, and paclitaxel-resistant cell lines (KF28тx and $\mathrm{KFr} 13 \mathrm{Tx}$ ) induced by exposing KF28 and KFr13 to doseescalating paclitaxel were compared and analyzed using cDNA microarray. Of 557 human cancer-related cDNA transcripts compared, 5 genes were found to be underexpressed and 5 genes overexpressed in the paclitaxelresistant KF28Tx, while another paclitaxel-resistant KFr13 had 5 underexpressed and 8 overexpressed genes. Among these genes, overexpression of the ATP-binding cassette subfamily (MDR-1), Rho guanine dinucleotide phosphate dissociation inhibitor beta (RhoGDI) and insulin-like growth factor binding protein 3 (IGFBP-3) was observed in both paclitaxel-resistant cell lines. Using real-time quantitative PCR, we confirmed the array results. We therefore conclude that IGFBP-3, RhoGDI and MDR-1 were correlated with paclitaxel resistance. Moreover, immunohistochemical
\end{abstract}

Correspondence to: Dr Masashi Takano, Department of Obstetrics and Gynecology, National Defense Medical College, Tokorozawa, Saitama 359-8513, Japan

E-mail: markuntkn@aol.com

Abbreviations: MDR-1, ATP-binding cassette subfamily; GDP, guanine dinucleotide phosphate; RhoGDI, Rho GDP dissociation inhibitor; IGFBP-3, insulin-like growth factor binding protein 3; GAPDH, glyceraldehyde-3-phosphate dehydrogenase; PBS, phosphate-buffered solution; CR, complete response; PR, partial response; $\mathrm{SD}$, stable disease; $\mathrm{PD}$, progressive disease; $\mathrm{DAB}$, diaminobenzidine hydrochloride

Key words: gene expression, insulin-like growth factor binding protein 3 (IGFBP-3), Rho GDP dissociation inhibitor beta (RhoGDI), MDR-1, ATP-binding cassette subfamily, immunohistochemistry staining was analyzed in 22 serous ovarian cancer tissues from patients who received paclitaxel-based chemotherapy, and RhoGDI overexpression was observed more frequently in non-responsers than in responders $(\mathrm{p}=0.004)$. RhoGDI expression proved to be a predictive marker of paclitaxel resistance not only in paclitaxel-resistant cell lines, but also in clinical samples.

\section{Introduction}

Paclitaxel (Taxol ${ }^{\mathrm{TM}}$; Bristol Myers Squibb, Oncology, Tokyo, Japan), one of the most active cancer chemotherapeutic agents known, is effective against a variety of human tumors, including ovarian carcinomas (1-3). The efficacy of paclitaxel is limited by the development of drug resistance in a population of surviving malignant cells. Defined molecular mechanisms for acquired tumor cell resistance to paclitaxel include overexpression of the drug efflux pump MDR-1 and differential expression of $\beta$-tubulin isotypes or $\beta$-tubulin gene point mutations (4-7). Mutations of the $\beta$-tubulin gene, however, might have a small role in ovarian cancer (8). Data also suggest that p53 status and mitosis checkpoint control are important in determining the sensitivity of cells to paclitaxel (9). In addition, it has been reported that paclitaxel was effective in inducing apoptosis in resistant sublines with a p53 mutation, suggesting pharmacological benefit of paclitaxel in the treatment of p53-mutated tumors (10).

We have reported that the induction of cisplatin resistance in ovarian cancer cells resulted in a sensitization to paclitaxel and the vice versa induction of paclitaxel resistance caused sensitization to cisplatin (11). Similarly, these phenomena were observed in patients with cisplatin-resistant ovarian carcinoma (12). However, there is little ex vivo clinical data and limited understanding of which, if any, of these mechanisms influence paclitaxel resistance in humans. Most studies regarding paclitaxel resistance have focused on only a few specific genes. Thus, we attempted to characterize the changes in gene expression profiles by evaluating differential gene expression between paclitaxel-sensitive and -resistant ovarian cancer cells and to explore markers with clinical significance. 


\section{Materials and methods}

Cell lines used and cell culture. KF28 is a single-cell clone of the human ovarian carcinoma cell line KF. KFr13 is a cisplatin-resistant subline derived from KF28 cells. The KFr13 subline was initially isolated as a single clone after repeated exposure of the parent KF28 cell line to escalating doses of cisplatin (13). Similarly, KF28Tx and KFr13 $\mathrm{Tx}$ are paclitaxel-resistant sublines derived from KF28 and KFr13 cells, respectively, after repeated exposure to escalating doses of paclitaxel (12). Cytotoxicity assay revealed that KF28Tx and KFr13 $\mathrm{Tx}$ showed about 11.5-fold and 4.9-fold resistance compared with KF28 and KFr13, respectively.

Preparation of RNA. Cultured cells were lysed in a buffer containing guanidium isothiocyanate and harvested by scraping, and total RNA was extracted using a modified AGPC method. mRNA was purified using a poly(A) purification kit (Oligotex-dT30; Takara Bio, Inc., Japan) according to the manufacturer's instructions. The quality of mRNA was assessed by OD 260/280 ratios and, mRNA was used only when the ratio was above 1.9.

RNA labeling, hybridization to the arrays. Human Cancer Chip, version 2.1 (IntelliGene ${ }^{\mathrm{TM}}$; Takara Bio, Shiga, Japan) was used for the studies with cell lines. This array consists of 557 cDNA fragments associated with human cancer, 12 types of human housekeeping genes for positive controls and normalization of two fluorescent signals, and 9 types of bacteria, phage and plant genes for negative controls. Each cDNA used for printing on the array has been sequenced and verified by the company. The chip was used to directly compare gene expression profiles between the paclitaxelsensitive and -resistant cell lines. To prepare the hybridization, prehybridization buffer (6X SSC, 0.2\% SDS, 5X Denhardt's solution, $1 \mathrm{mg} / \mathrm{ml}$ salmon sperm DNA solution) was placed on the array under a $22 \times 22-\mathrm{mm}$ glass coverslip and sealed with glue for $2 \mathrm{~h}$ at room temperature. Unsealed slides were washed with 2 X SSC and $0.2 \mathrm{X} \mathrm{SSC}$, and spun dry by centrifugation for $2 \mathrm{~min}$ in a $50-\mathrm{ml}$ tube at $3000 \mathrm{rpm}$. For each competitive array hybridization, fluorescent-labeled cDNA was synthesized using reverse transcription from the test cell mRNA in the presence of Cy5-dUTP (Amersham Pharmacia Biotech, Buckinghamshire, UK), and from the reference mRNA with Cy3-dUTP (Amersham Pharmacia Biotech) using a labeling kit (RNA Fluorescent Labeling Core kit; Takara Bio). For cell lines, two hybridization experiments were performed. One was KF28 versus KF28Tx in which mRNA from KF28 and KF28Tx were labeled with Cy3 and Cy5, respectively. Another was KFr13 versus KFr13 1 тx in which mRNA from KFr13 and KFr13тx were labeled with $\mathrm{Cy} 3$ and $\mathrm{Cy} 5$, respectively. For each reverse transcription reaction, mRNA $(1 \mu \mathrm{g})$ or total RNA $(80 \mu \mathrm{g})$ was mixed with an anchored oligo-dT primer (300 pmol) in a total volume of $10.3 \mu \mathrm{l}$, heated at $70^{\circ} \mathrm{C}$ for $5 \mathrm{~min}$ and immediately cooled on ice. The $5 \mathrm{X}$ first strand buffer $(4 \mu \mathrm{l})$, 10X dNTP mixture $(2 \mu 1)$, either $0.7 \mu 1$ of Cy3-dUTP or Cy5dUTP $(1 \mathrm{mM}), 1 \mu \mathrm{l}$ of RNase inhibitor $(40 \mathrm{U} / \mu \mathrm{l})$, and $1 \mu \mathrm{l}$ of AMV reverse transcriptase XL $(25 \mathrm{U} / \mu \mathrm{l})$ were added and incubated for $1 \mathrm{~h}$ at $42^{\circ} \mathrm{C}$, followed by the addition of another $1 \mu \mathrm{l}$ of AMV reverse transcriptase XL $(25 \mathrm{U} / \mu \mathrm{l})$ in a total volume of $20 \mu 1$, and incubated for another $1 \mathrm{~h}$ at $42^{\circ} \mathrm{C}$. RNA was degraded by heating at $70^{\circ} \mathrm{C}$ for $10 \mathrm{~min}$, and purified by centrifugation in a spin column (Centrisep; Princeton Separations, Adephia, NJ, USA). Two separate probes were combined, then $2 \mu \mathrm{l}$ of $5 \mathrm{X}$ competitor containing Cot-1 (Gibco BRL, Invitrogen Corp., Carlsbad, CA, USA), poly dA (Amersham Pharmacia Biotech) and tRNA (Sigma-Aldrich Japan, Tokyo) were added. After adding $50 \mu 1$ of $100 \%$ ethanol and $2 \mu \mathrm{l}$ of $3 \mathrm{M}$ sodium acetate ( $\mathrm{pH}$ 5.2), the mixture was cooled at $-80^{\circ} \mathrm{C}$ for $15 \mathrm{~min}$, followed by centrifugation at $15,000 \mathrm{rpm}$ for $10 \mathrm{~min}$, and pelleted down. For final probe preparation, the pellet was twice washed in $500 \mu 1$ of $70 \%$ ethanol, and eluted in $10 \mu 1$ hybridization buffer (6X SSC, $0.2 \%$ SDS, 5X Denhardt's solution, and $0.1 \mathrm{mg} / \mathrm{ml}$ salmon sperm solution). The probes were denatured by heating for 2 min at $95^{\circ} \mathrm{C}$, immediately cooled on ice, and centrifuged at $15,000 \mathrm{rpm}$ for $10 \mathrm{~min}\left(20-25^{\circ} \mathrm{C}\right)$. Supernatants were placed on the array and covered with a $22 \times 22-\mathrm{mm}$ glass coverslip. The coverslip was sealed with glue, and the probes were incubated overnight at $65^{\circ} \mathrm{C}$ for $14 \mathrm{~h}$ in a custom-made slide chamber with humidity maintained by underlying moist papers. Unsealed arrays were twice washed by submersion and agitation in $2 \mathrm{X} \mathrm{SSC} / 0.2 \% \mathrm{SDS}$ solution for $30 \mathrm{~min}$ at $55^{\circ} \mathrm{C}$, followed by $2 \mathrm{X} \mathrm{SSC} / 0.2 \% \mathrm{SDS}$ for $5 \mathrm{~min}$ at $65^{\circ} \mathrm{C}$, and $0.05 \mathrm{X} \mathrm{SSC}$ for $5 \mathrm{~min}$ at room temperature. The arrays were spun and dried by centrifugation for $2 \mathrm{~min}$ in a $50-\mathrm{ml}$ tube at $3,000 \mathrm{rpm}$ and immediately scanned.

Array quantification and data analysis. Following hybridization, arrays were scanned using a confocal laserscanning microscope (Scan Array 418; Affymetrix, Santa Clara, CA, USA). Separate images were acquired for $\mathrm{Cy} 3$ and Cy5. Data reduction was carried out using ImaGene 3.0 (BioDiscovery, Inc., Los Angeles, CA, USA). Each spot was defined by manual positioning of a grid of circles over the array image. For each fluorescent image, the average pixel intensity within each circle was determined, and a local background outside of the 3-pixel buffer range from the circle was computed for each spot. Net signal was determined by subtracting this local background from the average intensity of each spot. Signal intensities between the two fluorescent images were normalized by the intensities of the lambda poly A+RNA added as the internal standard for cell lines. Signal intensities of the fluorescent images for $\mathrm{Cy} 3$ and Cy5 were considered significant when they were $>4$-fold the average intensity of negative control signals (pUC18). Genes with consistently low signals $(<4$-fold the average intensity of negative control signals for both $\mathrm{Cy} 3$ and $\mathrm{Cy} 5$ ) across entire samples were omitted from the analysis. When the expression ratio $(\mathrm{Cy} 5 / \mathrm{Cy} 3)$ of a specific gene was $>2$-fold, the increase of gene expression was considered significant. When the expression ratio $(\mathrm{Cy} 5 / \mathrm{Cy} 3)$ of a specific gene was $<0.5$-fold, the decrease of gene expression was considered significant. The analysis of cDNA microarray was repeated 3 times independently to avoid technical errors, and the average value is presented.

Real-time RT-PCR. Total RNA was extracted by Trizol reagent according to the manufacturer's instructions (Life Technologies, Inc., Grand Island, NY, USA). cDNA was synthesized from $1 \mu \mathrm{g}$ total RNA by GeneAmp RNA PCR 
Table I. Differential gene expression between KF28Tx and KF28.

Underexpressed genes in KF28TX

Purine-rich element binding protein A

Plasminogen activator urokinase

Moesin

Cell division cycle 16 (CDC-16)

Insulin-like growth factor binding protein 2 (IGFBP-2)

Overexpressed genes in KF28Tx

Rho GDPa dissociation inhibitor $\beta$ (RhoGDI)

Insulin-like growth factor binding protein 3 (IGFBP-3)

Keratin 7

ATP-binding cassette subfamily (MDR-1)

Transforming growth factor $\beta$-induced (TGFßI)
Expression ratio $(\mathrm{KF} 28 / \mathrm{KF} 28 \mathrm{Tx})^{\mathrm{b}}$

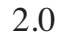

3.1

4.3 Expression ratio $(\mathrm{KF} 28 \mathrm{Tx} / \mathrm{KF} 28)^{\mathrm{b}}$

6.6

15.3

${ }^{\mathrm{a}}$ Guanine dinucleotide phosphate; ${ }^{\mathrm{b}}$ average value from three independent experiments.

kit (Perking-Elmer, Foster City, CA, USA). The obtained cDNA was diluted to a final concentration of $8 \mathrm{ng} / \mu 1$. The mRNA expression levels of $M D R-1$, RhoGDI, IGFBP-3, and an endogenous housekeeping gene encoding for glyceraldehyde-3-phosphate dehydrogenase $(G A P D H)$ as a reference, were quantified using real-time PCR analysis on the ABI Prism 7700 Sequencer Detector System according to the manufacturer's recommended protocol (ABI/PerkingElmer). All of the probes and primers used for the analysis were purchased from Applied Biosystems Japan (Assays-onDemand $^{\mathrm{TM}}$ gene expression products; Hatchobori, Chuo-ku, Japan). Briefly, a total $50 \mu 1$ solution containing test RNA of each cell line was mixed with $2 \mathrm{X}$ TaqMan Universal RTPCR Master Mix (Applied Biosystems), 1.25 $\mu \mathrm{M}$ of $40 \mathrm{X}$ Multiscribe and RNase inhibitor mix (Applied Biosystems), $2.5 \mu 1$ of TaqMan ${ }^{\text {TM }}$ Universal PCR Master Mix (Applied Biosystems). The reaction was initiated by reverse transcriptional reaction at $48^{\circ} \mathrm{C}$ for $30 \mathrm{~min}$, followed by AmpliTaq ${ }^{\mathrm{TM}}$ Gold activation at $95^{\circ} \mathrm{C}$ for $10 \mathrm{~min}$ and 40 cycles of two-step PCR reaction, and denatured at $95^{\circ} \mathrm{C}$ for $15 \mathrm{sec}$ and $60^{\circ} \mathrm{C}$ for $1 \mathrm{~min}$. The relative expression level of each gene was normalized against the GAPDH expression. Measurements containing three samples for each cell line were repeated 3 times to ensure the reproducibility of results.

Patient selection for immunohistochemical staining. Of 80 patients with primary epithelial ovarian cancer treated at the National Defense Medical College Hospital (Saitama, Japan) between 2001 and 2003, the following patients were selected: a) patients who received no chemotherapy prior to any surgical therapy; b) patients who harbored measurable residual tumors after initial debulking surgery; c) patients whose histologic subtype was serous adenocarcinoma according to the WHO criteria (14); d) patients treated with six courses of adjuvant chemotherapy using paclitaxel $\left(180 \mathrm{mg} / \mathrm{m}^{2}\right)$ and carboplatin $(\mathrm{AUC}=5)$ chemotherapy after the initial surgery; and e) patients who agreed to participate in the current study with written informed consent. The patients were divided into the following four groups according to their response to chemotherapy measured with CT or MRI: a) $\mathrm{CR}$ (complete response) group; b) PR (partial response) group; c) SD (stable disease) group; and d) PD (progressive disease) group. Responders were defined as patients with CR or PR, and non-responders were defined as those with SD and PD. A total of 16 responders and 5 non-responders were included in the study. Responders consisted of 12 stage IIIc, and 4 stage IV patients, and non-responders 3 stage IIIc, and 2 stage IV patients. The median age of patients was 53 years (range; 42-74 years) for responders and 55 years (range, 4565 years) for non-responders. There were 3 grade 1,7 grade 2 , and 6 grade 3 tumors observed in the responders and 1 grade 1,3 grade 2 , and 1 grade 1 tumors observed in the nonresponders.

Immunohistological stainings for MDR-1, RhoGDI and $I G F B P-3$. After reviewing the hematoxylin-stained sections, a paraffin block of the most representative sections were selected and cut into a 4- $\mu \mathrm{m}$ thickness. Immunohistochemical analysis was performed by the EnVision ${ }^{+\mathrm{TM}}$ system (15) (Dako Cytomation, Kyoto, Japan) to determine the protein expression of RhoGDI and IGFBP-3, and the LSAB ${ }^{+}$SystemHRP (Dako Cytomation) was used to evaluate MDR-1 expression. Sections were stained for the RhoGDI protein using a rabbit polyclonal antibody against human RhoGDI (1:200 dilution; Santa Cruz Biotechnology, Inc.), IGFBP-3 protein using a rabbit polyclonal antibody against human IGFBP-3 (1:200 dilution; Upstate Biotechnology, Lake Placid, NY), and MDR-1 using a goat polyclonal antibody (1:100 dilution; Santa Cruz Biotechnology, Inc.). For the positive controls of RhoGDI and IGFBP-3, sections of HeLa cells and $\mathrm{CHO}$ cells were used, respectively. Epithelia of the large intestine were used as positive controls for MDR-1. All of the sections were deparaffinized and rehydrated with xylene and a graded alcohol series. To inactivate endogenous 
Table II. Differential gene expression between KFr13тх and KFr13.

Underexpressed genes in KFr13 $\mathrm{Tx}$

Expression ratio $(\mathrm{KFr} 13 / \mathrm{KFr} 13 \mathrm{Tx})^{\mathrm{c}}$

Thyroid hormone receptor interactor 6

Keratin 4

PDGF $^{\mathrm{a}}$ associated protein

p53-induced protein

Farnesyl-diphosphate farnesyltransferase 1

4.8

Overexpressed genes in KFr13 $\mathrm{TX}$

Expression ratio (KFr13Tx /KFr13) ${ }^{\mathrm{c}}$

Interferon induced transmembrane protein 2

Ras homolog gene family member E

Signal transducer and activator of transcription 1

Rho GDP $^{b}$ dissociation inhibitor $\beta$ (RhoGDI)

Amphiregulin (schwammoma-derived growth factor)

Insulin-like growth factor binding protein 3 (IGFBP-3)

Interleukin $1 \alpha$

ATP binding cassette subfamily B (MDR-1)

10.4

aPlatelet-derived growth factor; ${ }^{b}$ guanine dinucleotide phosphate; ${ }^{c}$ average value from three independent experiments.

Table III. Real-time RT-PCR analysis of genes identified by cDNA microarray analysis reported as relative expression levels in paclitaxel-resistant cell lines compared with parental cells.

\begin{tabular}{lcc}
\hline & \multicolumn{2}{c}{ Fold change } \\
\cline { 2 - 3 } Gene & KF28Tx/KF28 & KFr13 2 Tx/KFr13 \\
\hline MDR-1 $^{\text {a }}$ & $10.8 \pm 0.5$ & $12.5 \pm 0.3$ \\
RhoGDI $^{\mathrm{b}}$ & $7.8 \pm 0.2$ & $2.5 \pm 0.2$ \\
IGFBP-3 $^{\mathrm{c}}$ & $5.6 \pm 0.1$ & $6.3 \pm 0.2$ \\
\hline
\end{tabular}

${ }^{\mathrm{a} A T P}$-binding cassette subfamily; ${ }^{\mathrm{b}} \mathrm{Rho}$ GDP dissociation inhibitor B; cinsulin-like growth factor binding protein 3.

peroxidase activity, sections were immersed in methanol containing $0.3 \%$ hydrogen peroxidase for $30 \mathrm{~min}$ at room temperature, then incubated in $2.0 \%$ blocking serum for the reduction of non-specific binding. The sections were incubated with primary antibodies in a humid chamber for $60 \mathrm{~min}$ at room temperature, followed by washing with PBS. For the visualization of RhoGDI and IGFBP-3, the EnVision $^{+}$fluid was applied to the sections for $2 \mathrm{~h}$ at room temperature, and diaminobenzidine hydrochloride (DAB) was used. The $\mathrm{LSAB}^{+}$System-HRP kit (Dako Cytomation) was used to visualize MDR-1 expression according to the manufacturer's recommended protocol. These sections were counterstained with Meyer's hematoxylin. For MDR-1, only cell membrane and nuclear staining were considered as positive expression. For RhoGDI and IGFBP-3, cytoplasmic staining was considered as positive expression. The proportion of positive stained cells was counted in more than 10 high power fields by two investigators who were blinded to the data of cell lines and patient characteristics. Immunostaining for the specimen was classified as positive when $>10 \%$ of cells were positive. Correlation was analyzed using the Chi-square test. A p-value $<0.05$ was regarded as significant.

\section{Results}

Gene expression profiles of ovarian cancer cell lines. In comparison with KF28 cells, KF28Tx cells showed significant overexpression in genes such as Rho Guanine dinucleotide phosphate dissociation inhibitor $\beta$ (RhoGDI), insulin-like growth factor binding protein 3 (IGFBP-3), keratin 7, ATP binding cassette subfamily B (MDR/TAP) member 1 (MDR-1), and transforming growth factor $\beta$-induced (TGFßI), and significant underexpression in genes such as purine-rich element binding protein $\mathrm{A}$, plaminogen activator urokinase, moesin, cell division cycle 16 (CDC-16), and insulin-like growth factor binding protein 2 (IGFBP-2) was observed in KF28Tx cells (Table I).

In comparison with KFr13 cells, KFr13 1 Tx cells showed significant overexpression in genes such as interferon induced transmembrane protein 2, ras homolog gene family member E, signal transducer and activator of transcription 1 (STAT1), RhoGDI, amphiregulin (schwammoma-derived growth factor), IGFBP-3, interleukin $1 \alpha$, and MDR-1, and significant underexpression in genes such as thyroid hormone receptor interactor 6, keratin 4, platelet-derived growth factor (PDGF) associated protein, p53-induced protein, and farnesyldiphosphate farnesyltransferase 1 was observed in KFr13 cells (Table II).

In the paclitaxel-resistant KFr13 $\mathrm{Tx}$ line derived from cisplatin-resistant KFr13 cells, the overexpression of more genes was observed compared to KF28Tx cells derived from its cisplatin-sensitive counterpart. Overexpression of RhoGDI, IGFBP-3 and MDR-1 was common to these two paclitaxelresistant cell lines.

Real-time RT-PCR analysis. Three up-regulated genes identified by cDNA microarray were validated using real- 
Table IV. Immunohistochemical reactivity of MDR-1, RhoGDI, and IGFBP-3 according to the chemotherapeutic response to paclitaxel-based chemotherapy in serous ovarian cancer patients.

Cases with overexpression

\begin{tabular}{lccr} 
Chemotherapeutic response & Responders & Non-responders & p-value $^{\mathrm{a}}$ \\
\hline MDR-1 $^{\mathrm{b}}$ & $2 / 16$ & $1 / 5$ & 0.676 \\
RhoGDI $^{\mathrm{c}}$ & $2 / 16$ & $4 / 5$ & 0.004 \\
IGFBP-3 $^{\mathrm{d}}$ & $5 / 16$ & $2 / 5$ & 0.717 \\
\hline
\end{tabular}

${ }^{a}$ Chi-square test; ${ }^{b}$ ATP-binding cassette subfamily; ${ }^{~}$ Rho GDP dissociation inhibitor $\beta$; dinsulin-like growth factor binding protein 3.

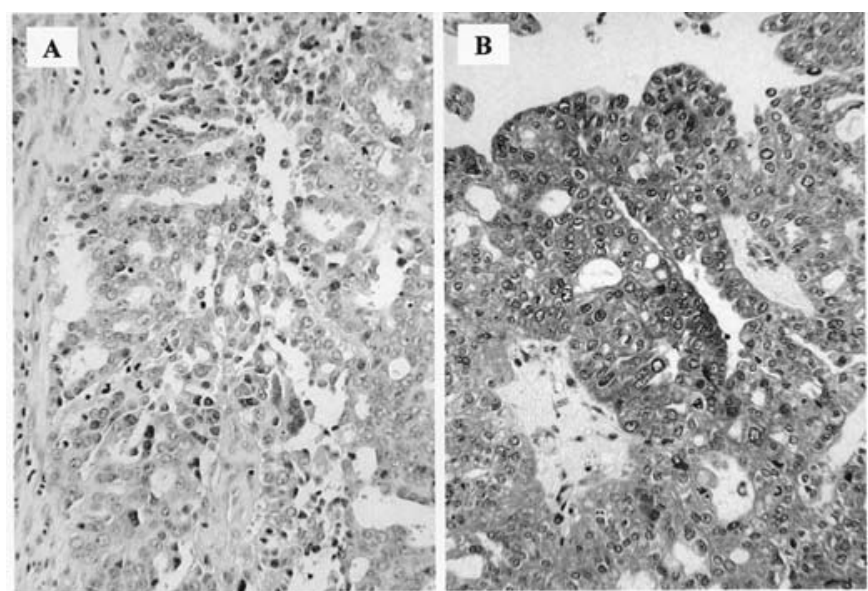

Figure 1. Representative immunohistological staining of RhoGDI of a responder (A) and non-responder (B) is shown. Sections of ovarian serous adenocarcinoma obtained at initial surgery were stained for RhoGDI protein using a rabbit polyclonal antibody. Overexpression of RhoGDI was significantly more frequent in non-responders than in responders $(60.0 \%$ vs. $12.5 \% ; \mathrm{p}=0.030)$. Original magnification, $\mathrm{x} 20$.

time RT-PCR analysis. Relative expression levels of genes in paclitaxel-resistant cell lines are shown in Table III. In all three genes analyzed, expression levels of paclitaxel-resistant cell lines were higher than that of parent cell lines.

Immunohistochemical staining of MDR-1, RhoGDI and IGFBP-3. Immunohistochemical reactivities of MDR-1, RhoGDI and IGFBP-3 according to the chemotherapeutic response to paclitaxel-based chemotherapy are shown in Table IV. Representative immunohistological staining of RhoGDI is shown in Fig. 1. MDR-1 overexpression was observed in 2 of 16 responders and 1 of 5 non-responders $(\mathrm{p}=0.676)$. IGFBP-3 overexpression was detected in 5 of 16 responders and 2 of 5 non-responders $(\mathrm{p}=0.717)$. Overexpression of RhoGDI was significantly more frequent in non-responders (4 of 5 cases) than in responders ( 2 of 16 cases). Immunoreactivity was not correlated with stage or histological grade (data not shown).

\section{Discussion}

An advantage of microarray analysis is that changes of many gene expression profiles can be simultaneously analyzed. The 557 cancer-associated genes were arrayed on the Human Cancer CHIP in our present study. Although the number of targets was small in comparison to other chips, the efficacy to detect alterations of gene expression in cancer is thought to be high because all targets are cancer-associated genes.

Underexpression in 5 genes and overexpression in 5 genes was observed in KF28Tx derived from KF28, whereas underexpression of 5 genes and overexpression in 8 genes was seen in KFr13Tx derived from KFr13. Overexpression of KFr13Tx was observed in more genes than that of KF28Tx. These results suggest that changes of gene expression by induction of cisplatin resistance might be amplified by the induction of paclitaxel resistance. Common overexpression of paclitaxel-resistant cell lines was observed in three genes (RhoGDI, IGFBP-3 and MDR-1), and the overexpression of these genes was confirmed with real-time RT-PCR analysis. Any common underexpression was not observed, suggesting that three up-regulated genes may contribute to the paclitaxel resistance. There have been several reports regarding overexpression of genes related to paclitaxel resistance. MDR-1 overexpression in ovarian cancer cell lines with paclitaxel resistance has been reported $(16,17)$. Similarly, we also confirmed MDR-1 overexpression in KF28Tx and KFr13 Tx cells (11). The role of MDR-1 is still uncertain. Some studies showed MDR-1 as a predictive marker of poor chemotherapeutic response $(18,19)$, but others did not $(20-22)$. As for histologic distribution, serous adenocarinoma often lacked MDR-1 expression, whereas clear cell adenocarcinoma showed overexpression of MDR-1 (23). More studies are required to further elucidate the detailed role of MDR-1 in the paclitaxel resistance of serous ovarian cancer patients.

Interestingly, overexpression of IGFBP-3 was commonly observed in both paclitaxel-resistant KF28 $\mathrm{TX}$ and KFr13 $\mathrm{TX}$ cell lines, however, there is no study describing the association of IGFBP-3 and paclitaxel resistance. Underexpression of IGFBP-2 was observed in KF28Tx, but not in KFr13 Tx. IGF systems are composed of two peptide ligands (IGF-I and IGF-II), and six high-affinity proteins (IGFBP-1 to IGFBP-6). The actions of IGFs may be modulated by the IGFBPs in either a positive or negative way, depending on tissue type and physiological/pathological status (24). Among IGFBPs, IGFBP-3 affects cell cycle and results in G1 arrest through IGF-independent mechanisms $(25,26)$, consequently allowing more time for DNA repair. IGFBP-3 has pro-apoptotic activity in vitro, and sensitizes cancer cells to apoptotic inducers such as ionizing radiation via induction of proapoptotic proteins such as BAX and Bad (27). It is possible that IGFBP-3 overexpression reduces the proliferative rate in 
human breast cancer cells (28), and may have consequently induced paclitaxel resistance. On the other hand, IGFBP-3 also acts as a growth stimulatory factor in vitro. IGFBP-3 enhanced IGF-stimulated DNA synthesis in breast cancer cells (29), and IGFBP-3 stimulates proliferation of prostate cancer cells even in the absence of serum or IGFs (30). Additionally, IGFBP-3 enhances EGF signaling and proliferative effects via increased EGF receptor phosphorylation and activation of p44/42 and p38 MAP kinase signaling pathway in breast epithelial cells (31). In our series of microarray analysis, EGFR expression was not significantly up-regulated in paclitaxel-resistant cell lines. Overexpression of IGFBP-3 in the paclitaxel-resistant cell lines might modulate the EGFR signaling pathway cascade and alter sensitivity to anti-cancer drugs. Although drug resistance in cancer is multifactorial, a slower growth rate represents a component of drug resistance. Paclitaxel has been reported to effectively induce apoptosis in cisplatin-resistant cells with a p53 mutation, via an intact p53-independent manner (10). Since the paclitaxel-resistant cell lines used in the present study have been established by repeated exposure to paclitaxel, overexpression of IGFBP-3 in the paclitaxel-resistant cell lines may be presented as an alternative of such apoptotic pathways.

Overexpression of the RhoGDI has been observed not only in the paclitaxel-resistant cell lines, but also in colorectal and fibrosarcoma cell lines that were resistant to mitoxantrone (32). Since GDI forms complexes with Rho, Rac or Cdc42, it is possible that GDI thereby blocks the apoptotic signal pathway mediated by Ras and c-Jun kinase. Such inhibition of the apoptotic signal pathway may induce paclitaxel resistance. It has been reported that the estrogen receptor (ER) transcriptional activation is induced through overexpression of RhoGDI by inhibiting RhoGTPases, and the RhoGDI signal is transduced to ER by the CREB-binding protein $(\mathrm{CBP}) / \mathrm{p} 300$ through the GRIP-1-dependent and -independent pathway $(33,34)$. Although ER expression was not significantly up-regulated in the present paclitaxelresistant cell lines, a Rho-ER axis might be associated with the induction of a paclitaxel-resistance phenotype. Further, it has been reported that the development of paclitaxel resistance is accompanied by overexpression of the cytokines/ chemokines interleukin 6 and 8, and monocyte chemotactic protein 1 (17). Britten et al showed that there is a significant Raf-1 kinase depending on paclitaxel resistance in human ovarian cancer cell lines and suggested that the Raf-1 kinase inhibitors can enhance paclitaxel sensitivity in ovarian cancer (35). Comparison between paclitaxel-sensitive and -resistant human ovarian cancer cell lines by differential display identified a new gene, TRAG-3 (Taxol resistance associated gene 3 ) of which mRNA is overexpressed in the Taxolresistant cell line (36). There is also a report of altered expression of specific ß-tubulin genes in paclitaxel-resistant ovarian cancers $(5,22)$. However, the altered expression of genes (interleukin 6, interleukin 8, Raf-1 kinase, TRAG-3 and specifically ß-tubulin) described above were not observed in the present cDNA microarray analysis. We demonstrated that RhoGDI overexpression was significantly correlated with paclitaxel resistance in clinical samples. The molecular function is unclear, but RhoGDI might be a candidate in predicting the chemotherapeutic response of ovarian cancers.
In the present study, we demonstrated that MDR-1, IGFBP-3 and RhoGDI were commonly overexpressed in the paclitaxel-resistant ovarian cancer cell lines, while only RhoGDI was significantly correlated with paclitaxel resistance in clinical samples with serous cystadenocarcinoma.

\section{Acknowledgements}

This study was supported in part by a grant from Cancer Circumvention New 10-Year Strategy for Cancer Control for the Ministry of Health Labor and Welfare, Japan.

\section{References}

1. Rowinsky EK and Donehower RC: Paclitaxel (Taxol). N Engl J Med 332: 1004-1014, 1995.

2. McGuire WP, Hoskins WJ, Brady MF, Kucera PR, Partridge EE, Look KY, Clark-Pearson DL and Davidson M: Cyclophosphamide and cisplatin compared with paclitaxel and cisplatin in patients with stage III and stage IV ovarian cancer. N Engl J Med 334: 1-6, 1996.

3. Wiseman LR and Spencer CM: Paclitaxel: an update of its use in the treatment of metastatic breast and ovarian and other gynecological cancers. Drugs Aging 12: 305-334, 1998.

4. Dunontet C, Duran GE, Steger KA, Beketic-Orerkovic L and Sikic BI: Resistance mechanisms in human sarcoma mutants derived by single-step exposure to paclitaxel (Taxol). Cancer Res 56: 1091-1097, 1996.

5. Kavallaris M, Kuo DYS, Burkhart CA, Regl DL, Norris MD, Haber M and Horwitz SB: Taxol-resistant epithelial ovarian tumors are associated with altered expression of specific $\beta$ tubulin isotypes. J Clin Invest 100: 1282-1293, 1997.

6. Gianna-Kakou P, Sackett DL, Kang YK, Zhan Z, Butters JT, Fojo $T$ and Doruchynsky MS: Paclitaxel-resistant human ovarian cancer cells have mutant $\beta$-tubulins that exhibit impaired paclitaxel-deriven polymerization. J Biol Chem 272: 17118-17125, 1997 .

7. Monzo M, Rosell R, Sanchez JJ, Lee JS, O'Brate A, Alberola V, Gonzalez-Larriba JL, Lorenzo JC, Nunez L, Ro JY and Martin C: Paclitaxel resistance in non-small-cell lung cancer associated with beta-tubulin gene mutations. J Clin Oncol 17: 1786-1793, 1999.

8. Lamendola DE, Duan Z, Penson RT, Oliva E and Seiden MV: Beta tubulin mutations are rare in human ovarian carcinoma. Anticancer Res 23: 681-686, 2003.

9. Wahl AF, Donaldson KL, Fairchild C, Lee YFL, Foster SA, Demers GW and Galloway DA: Loss of normal p53 function confers sensitization to Taxol by increasing G2/M arrest and apoptosis. Nat Med 2: 72-79, 1996.

10. Perego P, Romanelli S, Carenimi N, Nagnami I, Leone R, Bonettic A, Paolicchi A and Zuniho F: Ovarian cancer cisplatinresistant cell lines: Multiple changes including collateral sensitivity to Taxol. Ann Oncol 9: 423-430, 1998.

11. Yamamoto K, Kikuchi Y, Kudoh K and Nagata I: Modulation of cisplatin sensitivity by taxol in cisplatin-sensitive and -resistant human ovarian carcinoma cell lines. J Cancer Res Clin Oncol 126: 168-172, 2000.

12. Yamamoto K, Kikuchi Y, Kudoh K, Hirata J, Kita T and Nagata I: Treatment with paclitaxel alone rather than combination with paclitaxel and cisplatin may be selected for cisplatin-resistant ovarian carcinoma. Jpn J Clin Oncol 30: 446-449, 2000.

13. Kikuchi Y, Miyauchi M, Kizawa I, Oomori K and Katoh K: Establishment of a cisplatin-resistant human ovarian cancer cell line. J Natl Cancer Inst 77: 1181-1185, 1986.

14. Serov SF and Scully RE: Histological typing of ovarian tumors. World Health Organization, Geneva, 1973.

15. Sabattini E, Bisgaard K, Ascani S, Poggi S, Piccioli M, Ceccarelli C, Pieri F, Fraternali-Orcioni G and Pileri SA: The EnVision $^{+}$system: a new immunohistochemical method for diagnostics and research. Critical comparison with the APAAP, ChemMate $^{\mathrm{TM}}$, CSA, LABC, and SABC techniques. J Clin Pathol 51: 506-511, 1998.

16. Masanek U, Stammler G and Volm M: Messenger RNA expression of resistance proteins and related factors in human ovarian carcinoma cell lines resistant to doxorubicin, taxol and cisplatin. Anticancer Drugs 8: 189-198, 1997. 
17. Duan Z, Feller AJ, Person RT, Chabner BA and Seiden MU: Discovery of differentially expressed genes associated with paclitaxel resistance using cDNA microarray technology: Analysis of interleukin (IL) 6, IL-8, and monocyte chemotactic protein 1 in the paclitaxel-resistant phenotype. Clin Cancer Res 5: 3445-3453, 1999.

18. Yokoyama Y, Sato S, Fukushi Y, Sakamoto T, Futagami M and Saito Y: Significance of multi-drug-resistant proteins in predicting chemotherapy response and prognosis in epithelial ovarian cancer. J Obstet Gynaecol Res 25: 387-394, 1999.

19. Penson RT, Oliva E, Skates SJ, Glyptis T, Fuller AF Jr, Goodman A and Seiden MV: Expression of multidrug resistance-1 protein inversely correlates with paclitaxel response and survival in ovarian cancer patients: a study in serial samples. Gynecol Oncol 93: 98-106, 2004.

20. Baird RD and Kaye SB: Drug resistance reversal - are we getting closer? Eur J Cancer 39: 2450-2461, 2003.

21. Vasey PA: Resistance to chemotherapy in advanced ovarian cancer: mechanisms and current strategies. Br J Cancer 89: S23-28, 2003.

22. Mozzetti S, Ferlini C, Concolino P, Filippetti F, Raspaglio G, Prislei S, Gallo D, Martinelli E, Ranelletti FO, Ferrandina G and Scambia G: Class III beta-tubulin overexpression is a prominent mechanism of paclitaxel resistance in ovarian cancer patients. Clin Cancer Res 11: 298-305, 2005.

23. Ikeda K, Sakai K, Yamamoto R, Hareyama H, Tsumura N, Watari H, Shimizu M, Minakami H and Sakuragi N: Multivariate analysis for prognostic significance of histologic subtype, GST-pi, MDR-1, and p53 in stages II-IV ovarian cancer. Int J Gynecol Cancer 13: 776-784, 2003

24. Rajaram S, Baylink DJ and Mohan S: Insulin-like growth factorbinding proteins in serum and other biological fluids: regulation and functions. Endocr Rev 18: 801-831, 1997.

25. Ranke MB and Elmlinger M: Functional role of insulin-like growth factor binding proteins. Horm Res 48: 9-15, 1997.

26. Ma J, Pollak MN, Giovannucci E, Chan JM, Tao Y, Hennekens CH and Stampfer MJ: Prospective study of colorectal cancer risk in men and plasma levels of insulin-like growth factor (IGF)-I and IGF-binding protein-3. J Natl Cancer Inst 91: 620-625, 1999.
27. Butt AJ, Firth SM, King MA and Baxter RC: Insulin-like growth factor-binding protein-3 modulates expression of Bax and $\mathrm{Bcl}-2$ and potentiates $\mathrm{p} 53$-independent radiation-induced apoptosis in human breast cancer cells. J Biol Chem 275: 39174-39181, 2000 .

28. Wosikowski K, Silverman JA, Bishop P, Mendelsohn J and Bates SE: Reduced growth rate accompanied by aberrant epidermal growth factor signaling in drug resistant human breast cancer cells. Biochem Biophys Acta 1497: 215-256, 2000.

29. Chen JC, Shao ZM, Sheik MS, Haussain A, LeRoith D, Roberts CJ and Fontana JA: Insulin-like growth factor-binding protein enhancement of insulin-like growth factor-I (IGF-I)mediated DNA synthesis and IGF-I binding in a human breast carcinoma cell line. J Cell Physiol 158: 69-78, 1994.

30. Martin JL and Pattison SL: Insulin-like growth factor-binding protein enhancement of insulin-like growth factor-I (IGF-I)mediated DNA synthesis and IGF-I binding in a human breast carcinoma cell line. Endocrinology 141: 2401-2409, 2000.

31. Martin JL, Weenink SM and Baxter RC: Insulin-like growth factor-binding protein-3 potentiates epidermal growth factor action in MCF-10A mammary epithelial cells. J Biol Chem 278: 2969-2976, 2003.

32. Sinha P, Hutter G, Kotgen E, Dietel M, Schadendorf D and Lage H: Search for novel proteins involved in the development chemoresistance in colorectal cancer and fibrosarcoma cells in vitro using two-dimensional electrophoresis, mass spectrometry and microsequencing. Electrophoresis 20: 2961-2969, 1999.

33. Su LF, Knoblauch R and Garabedian MJ: Rho GTPases as modulators of the estrogen receptor transcriptional response. J Biol Chem 276: 3231-3237, 2001.

34. Su LF, Wang Z and Garabedian MJ: Regulation of GRIP1 and CBP coactivator activity by RhoGDI modulates estrogen receptor taranscriptional enhancement. J Biol Chem 277: 37037-37044, 2002.

35. Britten RA, Perdue S, Eshpeter A and Merriam D: Raf-1 kinase activity predicts for palitaxel resistance in TP53mut, but not TP53wt human ovarian cancer cells. Oncol Rep 7: 821-825, 2000.

36. Duan Z, Feller AJ, Toh HC, Makastorris T and Seiden MU: TRAG-3, a novel gene, isolated from a taxol-resistant ovarian carcinoma cell line. Gene 229: 75-80, 1999. 